Article

\title{
Economic Growth, Capitalism and Unknown Economic Paradoxes
}

\author{
Stasys Girdzijauskas *, Dalia Streimikiene and Andzela Mialik \\ Vilnius University, Kaunas Faculty of Humanities, Muitines g. 8, LT-44280, Kaunas, Lithuania; \\ E-Mails: dalia@mail.lei.lt (D.S.); andzelina.m@gmail.com (A.M.) \\ * Author to whom correspondence should be addressed; E-Mail: stasys.girdzijauskas@vukhf.lt; \\ Tel.: +370-37-422-566; Fax: +370-37-423-222.
}

Received: 28 August 2012; in revised form: 9 October 2012 / Accepted: 16 October 2012 /

Published: 24 October 2012

\begin{abstract}
The paper deals with failures of capitalism or free market and presents the results of economic analysis by applying a logistic capital growth model. The application of a logistic growth model for analysis of economic bubbles reveals the fundamental causes of bubble formation-economic paradoxes related with phenomena of saturated markets: the paradox of growing returnability and the paradoxes of debt and leverage trap. These paradoxes occur exclusively in the saturated markets and cause the majority of economic problems of recent days including overproduction, economic bubbles and cyclic economic development. Unfortunately, these paradoxes have not been taken into account when dealing with the current failures of capitalism. The aim of the paper is to apply logistic capital growth models for the analysis of economic paradoxes having direct impact on the capitalism failures such as economic bubbles, economic crisis and unstable economic growth. The analysis of economic paradoxes and their implication son failures of capitalism provided in the paper presents the new approach in developing policies aimed at increasing economic growth stability and overcoming failures of capitalism.
\end{abstract}

Keywords: failures of capitalism; economic paradoxes; market saturation; growing returnability; debt trap 


\section{Introduction}

The global economic crisis of 2008 and current financial problems of EU member states indicates structural problems facing today's capitalism. The issue of the future of capitalism has been continuously raised during discussions in World Economic Forum (WEF) 2012. The questions that one would rather expect to hear from the anti-capitalist protesters who have come to Davos were often pronounced by the WEF participants: has capitalism got a future? Is it fit for the 21st Century? The concept of "responsible capitalism" was introduced by some speakers. However, the founder of the forum, Klaus Schwab claimed that capitalism in its current form no longer fits the world.

The market economy is usually characterized by a fluctuation which regularly brings upturns and downturns. Each cycle of economy (from upturn to downturn) influences important macroeconomic factors - gross domestic product, inflation, deflation, level of unemployment, rate of interest, taxes etc. Increasingly recurring economic and financial crises in the world show that there are no answers to many important questions causing current structural economic problems [1].

Structural economic problems today are those that are not merely due to the normal business cycle, but are the result of more fundamental changes, some of which may be economic, social, political, etc. Structural problems are typically caused by a combination of the following: long term effects of technological change, unfavorable demographic changes, resource depletion, unwise government action and market saturation. Saturated markets initiate the operation of recently discovered yet for a long time operating problematic economic paradoxes: the paradox of growing returnability and the paradoxes of debt and leverage trap. These paradoxes occur exclusively in the saturated markets and cause the majority of economic problems including overproduction, economic bubbles and cyclic economic development. Unfortunately, these paradoxes have not been taken into account when dealing with the current failures of capitalism.

The aim of the paper is to apply logistic capital growth models for the analysis of economic paradoxes having direct impact on the capitalism failures such as economic crisis and, unstable economic growth. Seeking to achieve the target the following tasks were developed:

- To analyze advantages and failures of capitalism and to discuss the sustainability of capitalism;

- To define problems of economic investigations related to economic paradoxes;

- To develop logistic capital growth model and apply it for analysis of economic bubble formation;

- To analyze the economic paradoxes causing economic bubbles and crisis;

- To analyze issues of open and concealed overproduction;

- To generalize findings of analysis and define implications for the future of capitalism.

The paper presents new approach to some economic phenomena therefore some economic concepts are being treated more freely here.

\section{The Advantages and Failures of Capitalism}

There are many concepts of capitalism. The economic concept of "capitalism" as theorized today is a relatively recent phenomenon in the history of humankind, dating back little more than two centuries to the 1776 publication of A. Smith's The Wealth of Nations. Capitalism according A. Smith carries within it ideals of free trade, free market and "market freedom" that explicitly place the capitalist 
economist's faith in the individual and business, rather than in government and regulations. Karl Marx, arguably one of the most prominent socialists of the time, used it as a way to refer to a system of markets that favored capitalists at the expense of society.

Classical debates about the justifiability of capitalism, and especially the contrast between capitalism and communism, focused on the right to private property. John Stuart Mill (a defender of a modified version of capitalism) and Karl Marx (the most famous critic of all) supposed that capitalism is essentially defined by a system that relies on private property rights, and so they thought that the rejection of capitalism just is the rejection of private property [2].

In their era in both the United States and Europe, capital was achieving extraordinary power for newly emergent industrialists. This extraordinary accumulation of private power called for a new conception of capitalism; Adam Smith's conception of atomistic capitalism, where firms had little or no economic power, was hardly an adequate framework for such analyses [3]. At the same time, there were virtually no large-scale democratic states until almost the end of the 19th century. But the fact that governments had not mounted much by way of any successful attempts to embed markets in regulatory frameworks to protect labor, a critique brought up by Karl Polanyi, did not mean that they could not do so, as Marx implied, but only that it had not yet done so [3].

Many historians today tend to equate capitalism with markets, and the activities of market actors alone. Capitalism, for them, is a system of natural forces, i.e., supply and demand, that naturally tend toward equilibrium. The strength of this market-based conception of capitalism has been apparent for many years. The distinguishing contribution of my theory of capitalism is the third level of political authority. Recognizing the role of human agents, those within government in particular, is central to articulating a more accurate theory of capitalism as well as to understanding the realities of capitalist societies.

As the theories of Douglas North but especially of Friedman demonstrate, capitalism is often defined without a notion of human agency let alone government. Most commonly, capitalism is understood in Friedman-like terms as the process by which economic markets utilize the "invisible hand" of the price mechanism to spontaneously coordinate supply and demand between actors competing for particular goods and services. However, in practice, the visible hands of human agents are implicated in the process as they guide the invisible hand of the pricing mechanism. The pricing mechanism cannot come close to achieving an optimal coordinating role absent the effective work of the visible hand of government, often through legislative processes such as a parliament [3].

Therefore, capitalism is an economic and social system in which means of production are in private ownership and commodities, services and labor are being traded on the free market. In addition, profit is regularly being reinvested and invested in new technologies as well. The main feature of capitalism is that prices, income, distribution and investments are defined by markets with no interventions from the state. Sometimes capitalism is being defined as the system of free market or the development stage of industrial society. There are many failures of capitalism or market failures being investigated by various authors [4]. Market failure is a concept within economic theory wherein the allocation of goods and services by a free market is not efficient. That is, there exists another conceivable outcome where a market participant may be made better-off without making someone else worse-off. Classical market failures include monopolies, externalities, public goods, equity; information 
asymmetries, principal-agent problem etc. A. Kliman in his book about the failure of capitalism, defines the following main failures: economic crises; instability, under consumption and inequality [4].

There are several types of capitalism distinguished by various authors [5,6]. The current capitalism is often called mixed economy, post-industrial or informative society, modern capitalism etc. Amable's typology combines deductive (theoretical) and inductive statistical approaches and differentiates between five types or models of capitalism [6]:

- $\quad$ Asiatic (Japan, Korea)

- Continental (Germany, France, Belgium, Australia)

- $\quad$ Market-based (USA, UK, Australia, Canada)

- Mediterranean (Spain, Portugal, Greece, Italy)

- $\quad$ Social-Democratic (Denmark, Finland, Sweden)

According to B. Amable, Ireland, the Netherlands and Switzerland are between Market-based and Continental and Norway is between Social-Democratic and Continental [6].

According to Z. Norkus, the development of the production forces causes the replacement of one capitalist mode of production by another capitalist mode of production [5]. In the analysis of the development of production forces under capitalism, the ideas of Nikolai Kondratieff and Joseph A. Schumpeter on long business cycles are used. In the development of the production forces since industrial revolution in the late XVIII century, five technological economical paradigms are distinguished. Each of them is foundation of a separate capitalist mode of production.

Five capitalist modes of production corresponding to the five long Kondratieff waves are main evolutionary types of capitalism [5]:

(1) Local capitalism of individual and family enterprise owners;

(2) Local capitalism of small and middle closed joint stock companies (corporations);

(3) National capitalism of big private corporations;

(4) State regulated national capitalism of public corporations;

(5) Globalized transnational capitalism of investment funds.

This typology is most adequate for the analysis of the economic life in the advanced countries.

In this paper the main attention is being paid to globalized transnational capitalism. Though the free markets do not exist in reality the main apologist of free markets claim that the background of modern society is free market. The existence of free market institutes all over the world indicates the viability of free market beliefs. However, the current world markets are somehow regulated and there are some state interventions in all markets. These state interventions are inevitable. Though capitalism has many failures (often called market failures) there are no other better ways to distribute resources in economic systems. Capitalism allowed us to create high technologies and developed societies. The capitalistic means of production allowed us to created huge wealth and high quality of life in some countries for some groups of society. However, because of income inequality, which is also one of the main market failures, wealth is not distributed equally among countries and society members. Other important market of capitalism failures are related to cyclic economic development, economic crises, high unemployment, inflation rates, pollution and depleted natural resources. 
The biggest problem or failure of capitalism is cyclic economic development. Though some economists argue that cyclic economic development allows for renewal, economic and technical progress, and reallocation of resources and ensure efficiency of economic activities, the economic crisis and instability constitute a hard burden on the population.

The worst thing about cyclic development, crisis and unemployment well as inequality of income is the sudden appearance of the internal characteristics or internal failures of free markets. The existence of economic downturns and crisis is an essential feature of market economy. Seeking to understand the current economic situation and effectively manage a rapidly changing situation it is necessary to create a new approach in analysis of economic phenomena. It is especially important to understand economic paradoxes that have a heavy impact on current structural problems in economy.

The failures of capitalism began to flourish in the beginning of market relationship formations and creation of financial markets. The impact of overproduction upon markets had been noticed many years ago. However, the concealed overproduction due to financial instruments is still not obvious. Such a situation is easily explainable: concealed overproduction in opposition to open overproduction is happening in paradoxical way—by increasing returnability [7-9].

This situation can be understood but not justified. There is a lack of investigations in concealed overproduction and the investigations have been focused on unsaturated markets leaving saturated markets without necessary attention. The increasing returnability and search for fast profits eclipsed the threat of upcoming economic bubble. Of course they believe in self-regulating markets, but they also had an impact however much unsaturated markets can be described as self-regulating. However, during the burst of the economic bubble this never happens.

Capitalism cannot continue as a viable system much longer. The collapse of Western Capitalism can be expected in real-time in the near future. Current problems of market economy: volatility, flash crashes, trillions of $\$$ in derivatives, and money creation 'out of nothing' are representative of today's Ponzi Capitalism. The situation is not stable, and in the current period everything in the market economy is now relative, subjective, and fluctuating [10]. A new model or new system is necessary.

The recent economic crisis revealed some important economic paradoxes as having an impact on capitalism failures, such as growing returnability, credit trap, etc. These are mainly not new phenomena; however, the recent economic crisis indicated the importance of these paradoxes in the case of defining failures of capitalism.

\section{Sustainability of Capitalism}

There are many debates concerning sustainability of capitalism. The world crisis of 2008 had a particular impact on debates and questions about the future of capitalism. As it was addressed during the annual conference hosted by Capitalism and society center at University of Columbia in 2008, the most known world economists were discussing the future of capitalism. The debates concluded that the future of capitalism in unclear and that current type of capitalism cannot survive in the future without important changes.

Kenneth Rogoff has made an attempt to provide backgrounds for justifying the sustainability of capitalism [11]. In his works he tries to emphasize the positive sides and advantages of capitalism however he recognizes that technological innovations in financial markets do not mitigate risks. 
They increase the risk. He also raises the problem of sovereign debt but proposes to solve this problem by implementing more strict regulations of state finances to avoid huge debts. Like many other authors, K. Rogoff does not speak about market saturation by capital, open and concealed overproduction or about credit or leverage traps and other economic paradoxes which have not been explained so far. However, without taking these into account it is not possible to justify the idea of capitalism's sustainability. In the current age of globalization and integration, the phenomenon of economic cycles is becoming more and more obvious. The cycles are worsening and the crisis is becoming deeper. These processes are being regulated by the Governments; however, not effectively as there are no chances to prevent economic crisis without knowing their nature. Simply mitigating the impacts of a crisis is feasible. In such a context the sustainability of capitalism is doubtful.

According to J. Ikerd, capitalism inevitably dissipates, disperses, and disorganizes social energy because it weakens personal relationships [12]. Maximum economic efficiency requires that people relate to each other impartially, which means impersonally. People must compete rather than cooperate, if market economies are to function efficiently. When people spend more time and energy working - being economically productive - they have less time and energy to spend on personal relationships within families and communities. When people buy things based solely on price rather than buy from people they know and trust, personal relationships within communities suffer from neglect. Capitalism devalues personal relationships and disconnects people and thus dissipates, disperses, and disorganizes social energy. Capitalistic economies use people to do work, while doing nothing to restore the "social capital" needed to sustain positive personal relationships. There is no economic incentive for capitalists to invest in families, communities, or society for the benefit of future generations. Capitalists build relationships or contribute to social causes only when such contributions are expected to contribute to their profits or growth. Capitalists do not waste energy by investing in social capital. Capitalism inevitably tends toward social entropy [12].

Capitalism provides no economic incentives to sustain life on earth, but humans have the innate capacity and natural tendency to do so. Throughout human history, people have chosen families, communities, and societies over isolation, even when it was not in their short-term, individual self-interests to do so. Throughout human history, people have shown a sense of respect and reverence toward the earth, and have attempted to care for the earth, even when here was no incentive to do so. It is only within the past few decades that humans in large numbers have abandoned their basic nature as living, caring beings in pursuit of their narrow, individual self-interests. Not until the last few decades, were the social and ethical constraints removed, turning capitalism into an unsustainable system of extraction and exploitation [13]. To restore sustainability to capitalism, people must make conscious, purposeful choices to rebuild positive, mutually beneficial relationships with other people, not just for economic gains, but also to restore depleted stocks of social capital. No other economic system even approaches the efficiency of capitalism in utilizing economic capital to meet individual material human needs and wants. But, natural and social capital must be continually renewed and replenished to sustain economic capital. The sustainability of capitalism is simply too important to be left to the politicians and economists.

The issue of the future of capitalism has been raised during discussions in WEF 2012 continuously. The questions that one would rather expect to hear from the anti-capitalist protesters who have come to Davos were often pronounced by the WEF participants: has capitalism got a future? Is it fit for the 
21 st century? And if it has and is, how must capitalism change? Is capitalism working? Is the Western model of capitalism is still working? The concept of "responsible capitalism" was introduced by some speakers. However, the founder of the forum, Klaus Schwab claimed that capitalism in its current form no longer fits the world. Schwab spoke of a "dystopian future", where political and economic elites "are in danger of completely losing the confidence of future generations". Indeed, a global survey released just days before the start of Davos, the Edelman Trust Barometer, suggests there had been a sharp drop in public trust, not just in business but especially in governments around the world.

That capitalism is somehow broken has become one of Davos' most popular themes. TIME International Editor Jim Frederick hosted a panel discussion on the future of capitalism: Can a system that came of age in the 20th century serve the needs of 21st? Since then, no fewer than three other panels have been devoted to some variation of "fixing capitalism" or "remodeling capitalism." No one were arguing that capitalism should be scrapped wholesale, instead, the most rational arguments have pointed out that not only is capitalism the best system yet devised for enhancing the well being of the greatest number of people, but that it is also immensely supple and flexible. In 200 years, capitalism has already gone through several major development phases. But how will a global capitalism would look like for the 21 st century? Are more or less regulations necessary? Or which kind of capitalism: State Capitalism, like that practiced by China, Russia and many countries in the Middle East or Western Capitalism is more sustainable? A surprising number of participants in discussion about the future of capitalism clearly indicated that something is wrong therefore the main conclusion from discussions in Davos 2012 that capitalism needs a fundamental overhaul.

\section{Economic Paradoxes and Problems of Economic Investigations}

One of the causes of failures of economic investigations is the shaping of effective policies to overcome market or capitalism failures are due to a selection of inadequate models or methods for investigations. The proposal that economics lies somewhere between science and art [14] led to uncertainty and wrong choices in economic investigations. One of the examples is the theory developed by K. Marx.

There are many well-known scientists and economists arguing for the application of mathematical methods in economic analysis, i.e., Keynes, J.M, Schumacher, E.F. etc. The position was caused by the failures in applying mathematical methods in economics. However, these had a negative impact on economic analysis as without applying mathematical methods it is difficult to find right decisions in regulation of the economy. One can notice that many processes happening in economic systems are paradoxical: the same processes can have different impacts on other economic phenomena and sometimes unthinkable outcomes.

The economic paradoxes can be classified as theoretical paradoxes and empirical anomalies [15]. Adam Smith's diamonds and water paradox is a typical example of a rhetorical paradox. The paradox of thrift, Mandeville's paradoxes about private vices leading to public virtues, and Arrow's impossibility theorem are given as examples of fact of life paradoxes. The possibility of capital reversal or reswitching, Giffen's paradox, preference reversal paradox, St. Petersburg paradox, the Allais paradox, the Gibson paradox and the Leontief paradox are examples of the third category of paradoxes. There are also many paradoxes in capital theories and also the paradox of voting in the 
theory of choices. World economic events of the past two or three decades signify a sharp departure from those that have occurred in the decades of the 1950s and the1960s. In particular, the quick sequence of crises that have been taking place since the 1970s have triggered off many paradoxes and anomalies that have great analytical and policy significance [15]. The global economic crisis of 2008 revealed more paradoxes having impact on capitalism failures. The market saturation is not new phenomena however the recent economic crisis indicated its importance and impact on other capitalism failures. The failures of capitalism are related to economic paradoxes analyzed below.

Saturation. Traditionally, the term saturation means fullness, fullness to the limit, total filling and satiation. Such a concept is widely spread in the natural sciences and in the field of technology. The saturation of areal was investigated by biologists in the beginning of 19th century. In 1847, P.P. Verhiülst studied population growth and proposed a Logistic model or the "S-shaped" curve (abbreviated S-curve) of growth of some population. The initial stage of population growth is approximately exponential; then, as saturation begins, the growth slows, and at maturity, growth stops. Actually, a number of meanings of the term 'saturation' is known. For instance, let us take the saturation symbol - the dew point. It is the condition when the moisture of the atmosphere reaches $100 \%$ and the air cannot absorb more moisture. In medicine, precisely in oxygen therapy, blood saturation with oxygen is practiced; in physics, the magnetic saturation of materials is widely spread; in biology, the scientists consider the capacity of the population area and the saturation of the area related with the former. In chemistry, they speak of the saturation of solutions. A separate branch of chemistry is devoted to the analysis of this property of solutions. Solubility is the material's property to form monolithic systems, i.e., solutions including other materials. Solubility is the concentration of a fused material in its saturated solution. The solution in which the material does not fuse any more is considered to be saturated. For example, in $100 \mathrm{~mL}$ of room temperature water it is possible to fuse a bit more than $200 \mathrm{~g}$ sugar or only $35.9 \mathrm{~g}$ salt. The risen water temperature may increase the solubility, but only a little. It is important to note that the limit of solubility, although a little altered, remains more or less constant. Under certain conditions, it is possible to fuse a bigger amount of the solute, but then the solution will be oversaturated. An oversaturated solution will never remain stable: the surplus of the material under any effect will get crystallized and precipitated. Another type of solution, namely hard solutions, are also widespread. Thus, the phenomenon of saturation is very important in chemistry, physics, biology, medicine, etc. It might seem that economic structures avoid it. But from the abstract point of view, capital is also a type of population. Thereby we shall try to find out whether the 'solubility' of capital in the market is infinite or limited. The markets, or in other words, the 'solutes' are not identical: in some markets, the limited amount of capital is 'fused'; in others, it seems to be infinite [16-18]. Therefore, it is worth taking into account saturation while analyzing the conception of the market in more detail.

The market capacity may be understood as the amount of capital that might be effectively assimilated in an investment environment. Thus, all markets have their own capacity (for infinitive market the capacity is infinitive). In addition, market capacity depends on supply and demand interactions and is fluctuating. Due to the production and selling of more and more goods or services of the same type, gradually, the market gets filled up until finally market saturation is reached. We may arrive at the conclusion that each market has individual capacity. Only in the case when the 
market is infinite, it cannot be saturated, since its capacity is endless [18]. The economic development is being modeled by an increase of capital.

Capital. In economic theory capital is considered as the value of financial and physical funds, property or, wealth. In economics, capital, capital goods, or real capital refers to already-produced durable goods used in production of goods or services. The capital goods are not significantly consumed, though they may depreciate in the production process. Capital is distinct from land in that capital must itself be produced by human labor before it can be a factor of production. At any moment in time, total physical capital may be referred to as the capital stock, a usage different from the same term applied to a business entity. In a fundamental sense, capital consists of any produced thing that can enhance a person's power to perform economically useful work - a stone or an arrow is capital for a caveman who can use it as a hunting instrument, and roads are capital for inhabitants of a city. Capital is an input in the production function.

In economic models, capital is considered as an abstract wealth which is dependent upon time. The money which is not being used to create value added is just money but not capital. The money invested in production or other activities such as banking sector, services, etc., are capital. Logistic capital management is the management of capital in limited markets, i.e., markets having limited capacity to absorb invested capital $[19,20]$.

\section{The Models of Capital Growth}

Seeking to understand complex economic phenomena having impact on economic activities it is possible to use simplified models [1,9]. They would allow the specifics of capital accumulation starting from exponential growth and compound interest rates.

Suppose capital size $K$ depends upon time or is a function of time and the rate of capital accumulation is proportional to the capital size at each moment of time. The rate of growth of function is usually expressed by a derivative of this function. When the sum accumulated during period $t$ or accumulated capital can be presented by the following formula:

$$
\frac{d K}{d t}=m K
$$

By solving equation and considering that when $t=0, K=K_{0}$, and the coefficient of proportionality is $m=\ln (1+i)$, the following equation of compound interests is obtained:

$$
K=K_{0}(1+i)^{t}
$$

Here: $K$ - the size of capital accumulated during period $\mathrm{t}$; $t$-accumulation period, $K_{0}$ - the initial size of the capital, $i$-interest rate expressed in the same time units as $t$.

The formula of compound interests shows the infinitive growth however in reality the growth is always somehow limited. This model allows for the calculation of the capital size in $n$ periods. It is widely applied for the calculation of the present values of investment flows and allows us to compare various monetary flows.

During investigations of biological systems dynamics, the Formula (1) was modified by P. F. Verhülts in 19th century. In Formula (1) he applied the multiplier $\left(1-K / K_{p}\right)$ limiting the growth: and has obtained the following formula: 


$$
\frac{d K}{d t}=m \cdot\left(1-\frac{K}{K_{P}}\right) \cdot K
$$

Here: $K_{p}$ - the market capacity limiting the growth (potential capital).

By solving this equation the formula of logistic interests is developed [1]:

$$
K=\frac{K_{p} \cdot K_{0} \cdot(1+i)^{n}}{\left(K_{p}-K_{0}\right)+K_{0}(1+i)^{n}}
$$

In this equation $t$ is being replaced by $n$. In addition it is necessary to emphasize that Formula (1) is the specific case of Formula (4) then $K_{p} \rightarrow \infty$.

Using Formula 4 it is possible to develop the formula for capital logistic discount and assess the present value of capital:

$$
K_{0}=\frac{K_{P} \cdot K}{K+\left(K_{P}-K\right) \cdot(1+i)^{n}}
$$

Here: $K$ - the capital size accumulated during period $n, n$ - the period of accumulation, $K_{0}$ - the initial size of capital, $i$ - interest rate, expressed in the same nits as time $n, K_{p}$ - the market capacity limiting capital growth or potential capital.

If market capacity is large enough or if $K_{p} \rightarrow \infty$ then the compound interests discount formula is obtained:

$$
K_{0}=\frac{K}{(1+i)^{n}}
$$

There are many more growth models [1] including many growth factors (capital, labor, resources, technological progress, etc.) however, in this paper the capital growth model will be applied for analysis of capitalism failures. The limited growth or logistic growth model will be applied in the following analysis. The model of limited growth, often called logistic growth, may help to estimate capital (or market) saturation. The proposed logistic capital growth model is a somewhat transformed model of P. F. Verhült's - it includes the coefficients that are applied to the solution of economic problems. Further, the logistic capital growth model is applied for economic analysis of investments, discounting of monetary flows and allow us to model the genesis of economic bubbles formation. The economic bubbles are the main failure of capitalism and need to be investigated in more detail.

\section{Investment Bubble Modeling}

The main focus was allocated to financial investments and monetary flows of investments. The model of logistic discount (5) allows for the analysis of investment monetary flows and the possible alterations of their returnability depending on the degree of market capacity filling (filling rate) $K / K_{p}$ or on the size of the market niche. When modeling the price bubbles, one of the most perspective methods is the determination of the dependency of the logistic internal rate of return on the degree of market filling [9].

In modeling price bubbles the best way is potentially by evaluation of logistic internal rate of return based on the filling rate of the market. The logistic internal rate of return (LIRR) the following model might be applied [9]: 


$$
\sum_{j=0}^{n} \frac{K_{p} K_{j}}{K_{j}+\left(K_{p}-K_{j}\right) \cdot(1+i)^{j}}=0
$$

Here $K_{j},(j=\overline{0, n})$ the of money flows; when $K_{j}<0$ expenditures of the project; when $K_{j}>0$-revenues of the project.

According to definition the logistic internal rate of return - during one (the first) period is found by multiplying market capacity by a one unit diminished period of accumulated capital and divided by market niche. As we see, only a few simple operations are necessary, but the results and quality are practically the same as achieved during the analysis of a general case.

Let us take a concrete simplified example: at the beginning of the year, one monetary unit is being invested (e.g., $1 €, 1$ million $€$, etc.) and after one year the received income will make 1.2 monetary units. Formula (7) is applied to define internal rate of return $i$ then $K>K_{0}=1$ and $n=1$. In this case Logistic Internal Rate of Return — LIRR can be defined by the following simplified formula $(i=L I R R)$ :

$$
\operatorname{LIRR}(1)=\frac{K-1}{\left(1-K / K_{P}\right)}
$$

We obtained that the first period $\operatorname{LIRR}(1)$ is equal to the capital accumulated during one period minus 1 and divided by the coefficient limiting growth $\left(1-K / K_{p}\right)$.

As one can notice the Formula (8) is very simple but results are of the same value as applying the quite complicated Formula (7).

Using Formula 8 the dependence of internal rate of return on the degree of market filling with investment capital (i.e., market filling rate) is presented in Table 1 then $i K=1,1$ (interest rate 10\%), $K_{p}>1,1$. The market filling rate is expressed by ratio $K / K_{p}$.

Table 1. Market filling degree and logistic internal rate of return (LIRR) value.

\begin{tabular}{lccccccccccc}
\hline $\boldsymbol{K} / \boldsymbol{K}_{\boldsymbol{p}}$ & 0 & 0.1 & 0.2 & 0.3 & 0.4 & 0.5 & 0.6 & 0.7 & 0.8 & 0.9 & 0.99 \\
\hline $\boldsymbol{L} \boldsymbol{I} \boldsymbol{R} \boldsymbol{R}$ & 0.1 & 0.111 & 0.125 & 0.143 & 0.167 & 0.2 & 0.25 & 0.333 & 0.50 & 1 & 10 \\
\hline
\end{tabular}

It should be noted that Table 1 gives only the characteristic values; meanwhile, in a real situation, many more values might be taken. In the given example, the degree of market filling has been calculated when the minimum value of accumulated capital is 1.1 monetary units.

Based on data provided in Table 1, Figure 1 was created. The relationship between LIRR(1) and market filling rate is presented in Figure 1 in the case of $K_{0}=1$ and $K=1,1 ; K_{p}>1$.

Figure 1 provides an example then by investing 1 monetary unit in one year in which the investor receives $10 \%$ of interests. In this case, the Acc investment makes 1.1 of monetary unit. However, such a result is possible just in the case if the degree of market filling is equal to zero. When the market is not yet filled, the logistic internal rate of return and the usual internal rate of return are identical (i.e., 10\%). If the market is filled by $20 \%$, the internal rate of return of such investment (the logistic internal rate of return) makes $12.5 \%$. And if the market is filled by $50 \%$, the internal rate of return of such investment makes $25 \%$. If the degree of market filling (i.e., market filling rate) increases, the internal rate of return also increases. 
Figure 1. Dependence of the internal rate of return on the market filling rate in the case of investment.

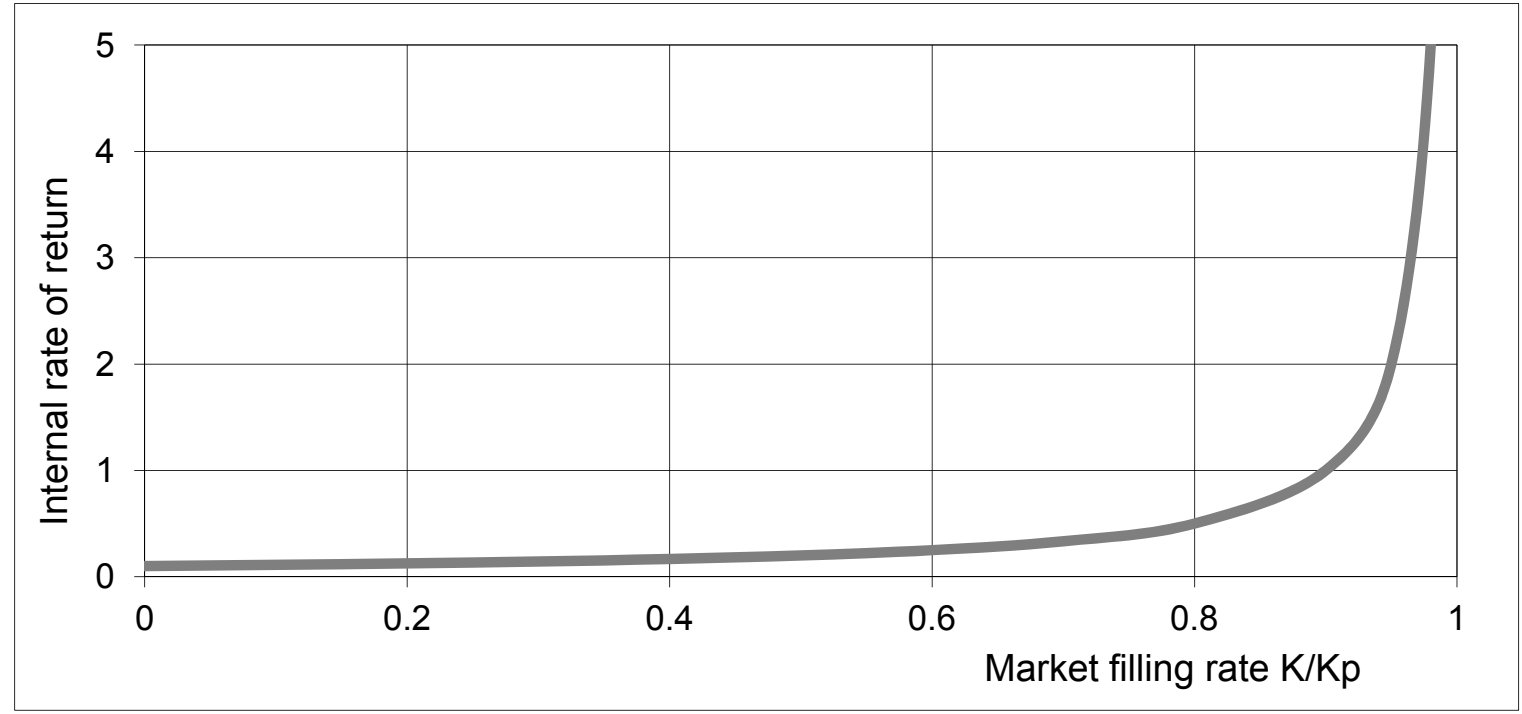

However, the growth is accelerating: when the market becomes half filled, the internal rate of return increases twice and reaches $40 \%$; when it is filled by $90 \%$, the initial internal rate of return increases 10 times. Finally, when the market is filled by $99.9 \%$, the initial internal rate of return increases for 100 times. Such growth caused by increasing market saturation forms a price bubble and at the same time initiates concealed overproduction in the market.

This elementary diagram shows the reason for an investment bubble formation, i.e., the limited nature of the market. In an infinite (or open) market, returnability is constant and therefore the bubble does not occur. In the partially or completely limited markets, such as the market of property, rare goods, etc., the bubbles are formed not due to the irrationality of the market participants, as some economists think, but, contrariwise, due to their excessive rationality - their wish to earn much or even become very rich under the conditions of growing returnability.

In the example we have shown the simplest case. When modeling market filling in the general case, i.e., when there is more than one assessed period and more than one member of the monetary flow, similar results are achieved. An exception might be found only in the fact that accumulated capital may exceed the determined market capacity - in other words, the market may be not only saturated but even oversaturated with capital. Yet, the model we have analyzed above does not allow for the prediction of an oversaturated market.

The current concept of economic bubble was developing through many years [21-26]. Though economic bubbles have been formatting since creation of free market they were not treated as economic phenomena. A. Smith in his work The Welt of Nations stressed in 1776 that the biggest profits are being achieved then the company or even country is being $\mathrm{n}$ the threshold of bankruptcy. The can be understood as the reference to economic bubbles. However for most market participants the economic bubbles were understood as fraud or criminal issue. Seeking to prevent fraud in England in the 18th century, the Bubble Act was issued. The introduction of this law was caused by the bankruptcy of South Sea Company in 1720. During these times the fraud companies were called soup bubbles. In all times the nature of a bubble to generate huge profits attracted a lot of cheats. 
Up to now there have been several concepts of the bubble and explanations of their genesis. The most comprehensive definition of economic bubble was developed by C. P. Kindelberger: the bubble is the sharp increase in the price of certain wealth during long period then the initial price increase creates the expectations of further increase and attracts new buyers interested in obtaining profits due to trade in wealth instead of acquisition of this wealth as measure to increase income [27]. However, this definition does not reveal the fundamentals of economic bubbles' formation.

According to logistic analysis [7], an economic bubble is the increase of price of wealth in certain markets due to market saturation which in the beginning is distinguished by moderate increase and later transitive to steep increase. The market saturation causes increase of returnability on the market which in turn causes an increase in activities of short-time investors or speculations having further impact on saturation of market. Such an explanation of economic bubbles reveals the causes of economic bubbles' formation and the condition of stable economic growth as well as opportunity to manage formation of economic bubbles.

The fundamental explanation of causes for bubble formation allows us to state that economic phenomena such as increasing returnability in saturated markets exists. This is an economic paradox as it cannot be explained by classical economic theory which do not takes into account market saturation. The market saturation is the main factor having a paradoxical impact on economic and capital growth: in increasing saturation of markets (at the same time as an increase of overproduction) the profitability is increasing instead of diminishing. The logistic analysis helps to reveal this economic paradox and to extend the boundaries of classical economic theories. Therefore, the revealing of economic paradoxes has a major impact on current economic problems and market failures and allows us to deal more efficiently with occurring problems such as cyclic economic growth, economic bubbles and crisis.

\section{The Paradox of Growing Returnability}

The performed modeling reveals the main result of the logistic analysis - the impact of the degree of market filling on investment returnability or, in other words, the paradox of growing returnability. Logically, we may easily arrive at the conclusion that with the growth of the market filling with capital, i.e., saturation, the conditions for capital growth get worse. It might seem that it should have a negative impact on returnability, i.e., that returnability should gradually decrease until it reaches zero. Yet, the models show a different situation, and not only the models. The calculations are confirmed by reality itself. If we analyze the cases of market saturation more attentively, we shall see that economical heating and bubble formation have been determined by immoderate investing. Moreover, in economics the saturation mechanism was invented rather long ago - it involves securities, their future transactions, allowing for the formation of surplus liquidity, hazard auctions (in the case of rare selling goods), etc.

It is easier to observe the paradox of growing returnability by analyzing an inverse sequence of events: at the beginning, the possible economic bubble is identified and then the analysis is made to find out whether it is related with the limited or partially limited market and whether that market was saturated (especially on the basis of securities). There are lots of such examples. For instance, let us take the famous 17th century tulip bulb mania in Holland, when it was possible to buy a house in Amsterdam for one bulb. Yet, the market was soon saturated when the future harvest of unplanted tulip 
bulbs as sold in the exchange. It is interesting to note that even then a big part of the customers used the borrowed means for making deals. Although it was not a typical case at that time (the capitalist system was not formed yet), it well illustrates the fatal consequences of market saturation. Similar stories frequently occur in our times as well.

\section{The Credit Trap Paradox}

Alongside the paradox of growing returnability is another similar phenomenon emerges due to the same reason, market saturation. It is the paradox of debt or credit trap. We might define it in the following way: if investment is made in the market of limited capacity, the speed of the growth of the borrowed capital (debt) exceeds the speed of the private capital growth. Moreover, after an adequate number of periods the difference in the speed of growth that was rather inconsiderable at the beginning essentially increases. Consequently, if the market is not saturated, both the private and borrowed capital increase identically.

Figure 2 shows the alteration with time of two investments identical in the absolute quantity that are equal to 1 monetary unit. It has been calculated with the use of the compound interest model (2) or the logistic interest model (4), when market saturation is equal to 0 . We see that the evolution of both private and borrowed capital is the same except that the mark of the borrowed capital is negative. Thus, the sum of both quantities at any moment of time remains equal to 0 . The situation is different if the investment market is of limited capacity.

Let us analyze the growth of capital with the use of the logistic growth model (4). While modeling the accumulation of capital it is necessary to estimate the specificity of the accumulation of the borrowed capital. As mentioned above, if accumulation is modeled with the help of the compound interest model, the dynamics of both private and borrowed capital is identical (Figure 2). Meanwhile, the logistic model reveals the specific behavior of the borrowed capital: the dynamics of the borrowed capital is much higher than that of the private capital.

Figure 2. Dynamics of private and borrowed capital under free market conditions.

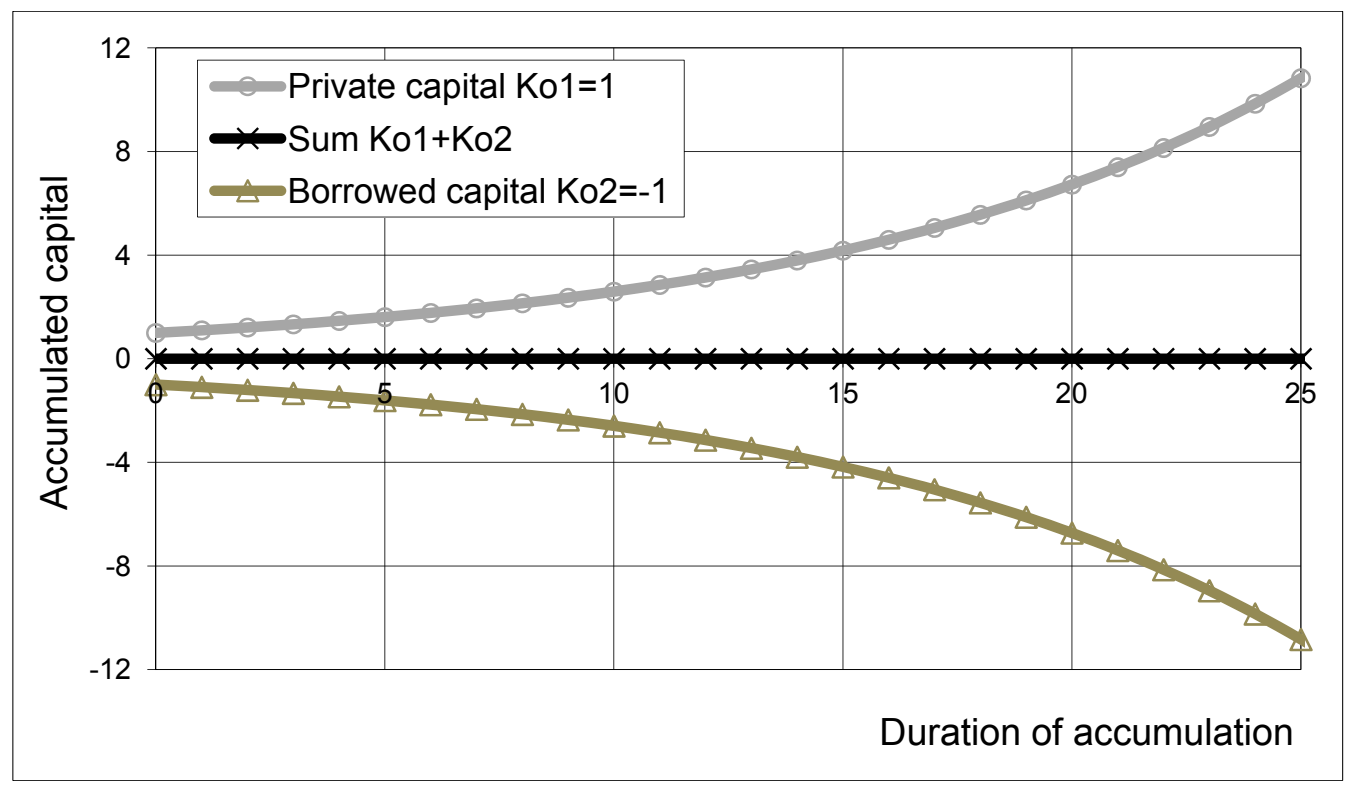


Figure 3 shows the dynamics of logistic growth of an investment with a negative member. The investment contains two components - a positive member, or private capital, that is equal to 1 relative monetary unit and a negative member, or debt that is also equal to 1 monetary unit. In this case, market saturation makes $10 \%$ and the interest rate of the investment is $10 \%$. The middle curve of the diagram shows the overall alternation. Here we observe that only at the very beginning the overall member remains equal to 0 ; later on it starts decreasing and remains negative. Hence, the investment that contains the private and borrowed capital of the same amount suffers a loss from the very beginning of investing.

Figure 3. Logistic dynamics of investments with negative member when the rate of return is $10 \%$ and market saturation makes $10 \%$.

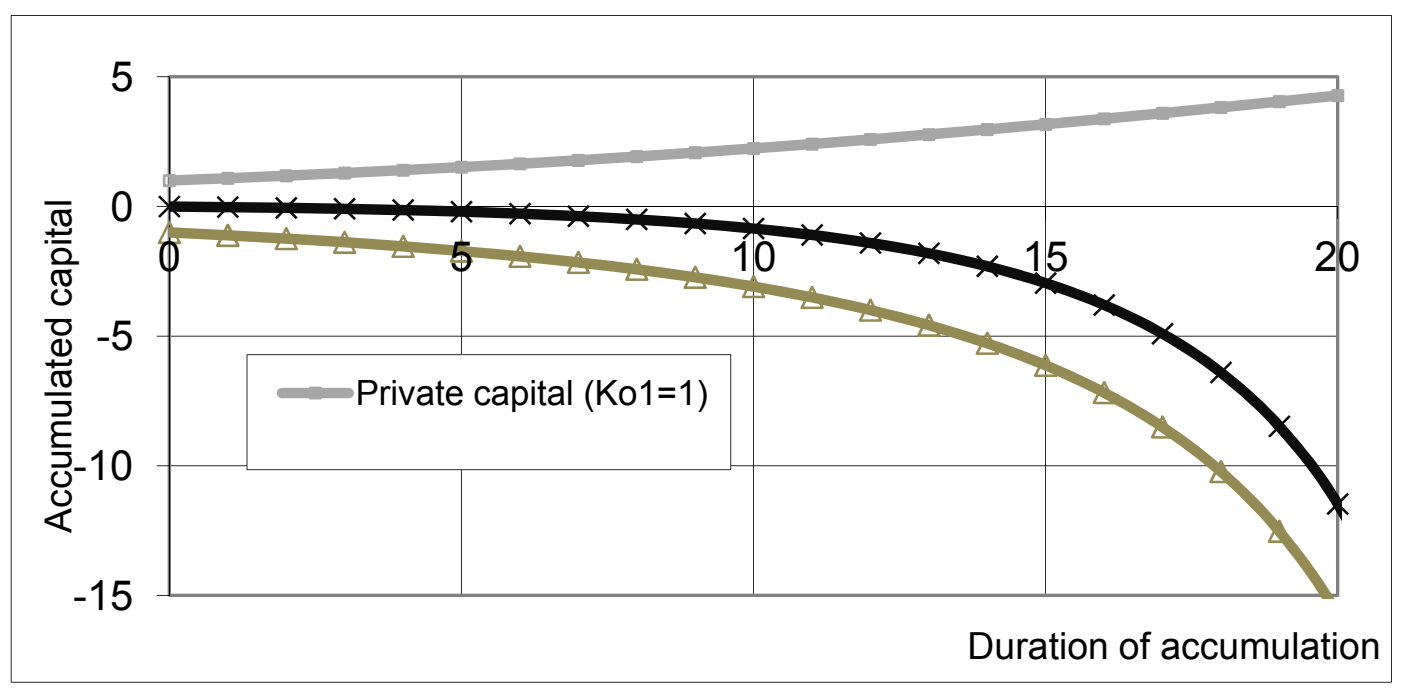

Therefore, with the increase of market saturation the degree of loss gets higher. The same situation is observed with the increase of interest rate [28-30]. The paradox related to the credit trap is the leverage trap.

\section{Leverage Trap}

In bank activities, financial leverage is understood as the ratio between the borrowed and the private capital. In other words, it is the impact on the general level of returnability when an investment is financed at the expense of both the private and borrowed capital. How does it work in bank practice? Let us discuss a particular example. The investor of securities who possesses a certain, yet, to his mind, inadequate sum of money is going to invest it into the securities of Company X. He appeals to the bank to find out the possibilities for buying the determinate securities and borrowing the deficient sum. The essence of such a deal is that it is possible to buy the profitable securities for the borrowed money and at the same time use it as a deposit thus paying smaller interest for the obtained loan than for the securities. In bank practice it is accepted that when possessing one relative monetary unit it is possible to borrow the sum up to 2 more monetary units of the same value. Thus, the bank client has the possibility to borrow and invest a three times higher sum than he disposes at the moment. It is an alternative possibility, especially when the securities of high profitability are bought and the bank interest is rather low. Nevertheless, the banking practice has had bitter experience and warns that 
investment with leverage is a rather risky occupation. The risk sources are not clear and therefore it is necessary to examine in detail the prerequisites for successful investment as well as the reasons for the possible failures. One possibility it is to work out a mathematical model and with its use to analyze the process of investment [1]. The main focus is on leverage and the model of interest assessment. Leverage is the multiplier or coefficient that quickens the growth of capital. Ignorance regarding the situation of the market, the processes when the leverage effect is used operating in it as well as their underestimation form the major risk of leverage investment. The trade in the saturated market is the potential threat for experiencing a financial crisis.

\section{Open and Concealed Overproduction}

Under market conditions the producer cannot precisely calculate the demand of his production for a long period in the future. Sometimes the situation arises when amount size of production is relatively higher than the demand which lasts for a rather long time, and the search for the new markets does not bring positive results. Such a situation is known as market overproduction. It occurs when more production is made than the physical and juridical persons having a necessary purchasing power may consume. In other words, when production is consumed moderately, it is not bought with the speculative intentions or for the sake of accumulation, since the prices fall down and accumulation of goods brings losses.

The producer forms the supply by relying on the potential demand of the product and its price. He makes a choice regarding the amount of goods that he will produce and supply in the market. The law of supply states that, when the price of the product increases, but under other equal conditions, the amount of supply also increases. The opposite statement is in operation as well: with the decrease of the demand, the supply decreases as well, not to mention the prices. Thus, due to overproduction the prices usually fall.

Although prices most often fall due to a too high supply, nevertheless, their surplus may coincide with the shortage of the same goods for some particular category of the customers. After the fall of the prices some of them will manage to obtain a certain part of the surplus of commodities. That is why the effect caused by overproduction will not be so significant and overproduction will remain open overproduction. Such overproduction occurs in open markets. Actually, the discussed factors perform the function of market self-regulation (i.e., overproduction is stemmed by the falling prices) and therefore have been widely advertised by the supporters of free market idea [1].

However, there exists another type of overproduction - it is the so-called concealed overproduction. It is formed in the limited (closed) markets. A limited market is such a market when one or both sides making a deal are directly related with a particular object of the market or their relationship is based on the territorial (geographical) principle. As discussed above, in the limited market, overproduction is related to market saturation and the growth of prices. The growing prices, in their turn, increase production and, consequently, increase overproduction. Such a situation is called 'market heating', which determines the surplus liquidity. Hence, the following question arises: what maintains such overproduction? The answer is that, at the beginning, concealed overproduction is maintained by growing returnability. Later on, speculative demand is added, in other words, a wish to earn more at 
the expense of the growing market. Such overproduction is promoted by various financial instruments. That is why concealed overproduction misbalances the market rather than positively controls it.

When concealed overproduction occurs, the demand of production itself increases rather than decreases. Its growth increases the prices. However, it should be noted that, in a real situation, the consumer does not need such an amount of production. The increased demand is determined by the speculation needs, i.e., a wish to gain profit by reselling a marketable product. As we know, securities are especially welcome in such a case. Unfortunately, due to some (often accidental) reasons the demand and surplus liquidity disappear; a sudden concealed overproduction turns into ordinary (i.e., open) overproduction. With such a sudden alteration of the situation the economic decline or crisis begins.

The demand forms market capacity. Therefore, special attention should be given to the dynamics of demand and dynamics of market capacity. Although in our models market capacity is regarded as steady, in real situations, it is highly dynamic and depends on many external and internal factors. Market capacity is mostly influenced by the general demand that, in its turn, is equal to the sum of real and speculative demand.

\section{Implications of Economic Paradoxes}

The analyzed economic paradoxes can be allocated to unknown paradoxes. These unknown paradoxes change the free market concept. The logistic analysis applied in this paper shows that free market can only exist in the initial phase of every market formation, i.e., in this case the market is not saturated. The saturation of markets distorts the self-regulation of markets. In saturated markets, because of the increasing returnability paradox, the risks of overheating and burst bubbles increases.

What is the economic meaning of the saturation concept? The saturation is related to market capacities, i.e., to the ability of the market to absorb the certain maximal amount of the capital. However, in the end, investments are expressed in certain production: goods and services. Here we can notice that saturation is directly related to the filling in of a market by certain production. If market capacity is limited, i.e., the demand for production is finite then it is possible to define the degree of market saturation. Therefore, it is possible to talk about overproduction in more broad way, especially in the case of sudden shrinkage of the market (decrease in demand) then, the certain amount of production circulating in the market is redundant. In this way, in terms of logistic analysis, saturation and overproduction are closely related concepts. The overproduction in its own way means economic stagnation, unemployment and decrease in welfare.

Unknown economic paradoxes such as increasing returnability and debt trap were the major obstacles or the free markets and capitalism development. As increasing returnability covers concealed overproduction the overproduction became a steady plague harming the image of capitalism as the efferent economic system to create welfare. Capitalism is concurrent to credits; credits allow us to achieve rapid economic growth and a high level of welfare. However, in the conditions of overproduction the credits suddenly turn into a debt trap causing the final collapse of economy formerly damaged by economic bubble. 


\section{Conclusions}

There are the following main failures of capitalism relevant to structural economic problems: deepening and increase of frequency of economic crisis, inequality and instability. The economic bubbles have major impact on the depth of economic crisis and its continuity. However, the state policies can play a significant role in mitigating these negative impacts.

Without knowing the nature and genesis of the economic bubbles formation, without understanding of the main economic paradoxes having impact on economic bubbles formation it is impossible to develop adequate policies.

The main economic paradoxes having direct impact on the failures of capitalism analyzed in this paper are related with structural economic problems due to saturated markets. Saturation of the market destroys the sustainability of economic development as saturated market becomes very profitable; although at the same time it becomes unstable: a small decrease in saturation can cause a significant drop in profitability and thus initiate a panic in the market. In order to influence or manage situations of crises, the saturation of the market or overproduction must be prevented by state policies.

The main failures of capitalism are related with economic paradoxes such as growing returnability and credit trap. These paradoxes have not yet been widely recognized by the economic experts and state policies are not developed to address them.

The paradox of growing returnability that causes the formation of price bubbles is the central one. It evokes overproduction within the market. In the beginning, such overproduction is concealed, and it becomes open only after the burst of the bubble.

The paradox of debt trap that occurs solely in the saturated markets evokes the debt crises of various levels. The market into which the borrowed capital is invested must be unsaturated, i.e., the market must be unheated, without overproduction, whether open or concealed. In the saturated markets, investment with the financial leverage is not only risky but often disastrous.

In order to avoid the negative consequences of market saturation it is vital to determine strict rules to control the operations with certain types of securities. It is urgent to start establishing a monitoring system of the local markets and then of the global system that would allow us to observe the saturation of the world markets.

The concept of responsible capitalism is also worthy of attention as it provides additional levers for increasing economic stability and equity. Responsible capitalism allows corporations to continue making money and delivering to needs, safe in the knowledge that the wider interest of people and planet are being taken care of.

\section{References}

1. Girdzijauskas, S. Sovereign Debt Crisis: Logistic Analysis; Vilnius University Press: Vilnius, Lithuania, 2011.

2. Brenkert, G.C.; Beauchamp, T.L. The Oxford Handbook of Business Ethics; Oxford University Press: New York, NY, USA, 2009.

3. Scot, B.R. The Concept of Capitalism; Springer: New York, NY, USA, 2009.

4. Kliman, A. Failure of Capitalism; New York, NY, USA, 2010. 
5. Norkus, Z. Kondratjevo bangos ir kapitalizmo tipai. Sociologija 2010, 2, 13-33.

6. Amable, B. The Diversity of Modern Capitalism; Oxford UP: Oxford, UK, 2003.

7. Girdzijauskas, S. Logistic Theory of the Capital Management: Deterministic Methods; Vilnius University Publishing House: Vilnius, Lithuania, 2006; p. 232.

8. Girdzijauskas, S.; Štreimikienè, D. The Role of Logistic Analysis in Economic Theory; Economics: Almaty, Republic of Kazakhstan, 2010; pp. 706-722.

9. Girdzijauskas, S.; Streimikiene, D. Logistic Analysis of Business Cycles, Economic Bubbles and Crises. In Business Intelligence in Economic Forecasting: Technologies and Techniques; Hershey: New York, NY, USA, 2010; pp. 45-64.

10. Girdzijauskas, S.A.; Moskaliova, V. Instability Modeling of Financial Pyramids. In Proceedings of the 5th International Scientific and Practical Conference Environment, Technology, Rezekne, Latvia, 16-18 June 2005; Rezeknes Augtskola: Rezekne, Latvia, 2005; pp. 26-32.

11. Rogoff, K. Is Modern Capitalism Sustainable? Available online: http://www.projectsyndicate.org/commentary/rogoff87/ (accessed on 12 September 2012).

12. Ikerd, J. Sustainable Capitalism: A Matter of Common Sense; Kumarian Press: Columbia, SC, USA, 2005.

13. Alperovitz, G.; Daly, L. Unjust Deserts: How The Rich Are Taking Our Common Inheritance and Why We Should Take It Back; New Press: New York, NY, USA, 2008.

14. Brooks, D. The Return of History. The New York Times, 25 March 2010. Available online: http://www.nytimes.com/2010/03/26/opinion/26brooks.html (accessed on 12 September 2012).

15. Panchamukhi, V.R. Five recent paradoxes and anomalies of economics. Asia Pac. Dev. J. 2000, $7,1-31$.

16. Girdzijauskas, S.; Pikturna, A.; Ivanauskas, F.; Merkevicius, E.; Moskaliova, V. Investigation of the Elasticity of the Price Bubble Functions; Technika: Vilnius, Lithuania, 2008; pp. 131-136.

17. Girdzijauskas, S.; Streimikiene, D. Logistic Growth Models for Analysis of Stocks Markets Burbles. In Proceedings of the International Conference of Financial Engineering, London, UK, 2-4 July 2008; Volume I-II, pp. 1166-1170.

18. Girdzijauskas, S.; Streimikiene, D. Application of logistic models for stock market bubbles Analysis. J. Bus. Econ. Manag. 2009, 10, 45-51.

19. Streimikiene, D.; Girdzijauskas, S. Sustainable Development and Logistic Growth of Resource Consumption. In International Business Development: Globalization, Opportunities, Challenges: International Scientific Conference 15-16 May 2008, Vilnius, Lithuania: Collection of Articles; Vilnius University Publishing House: Vilnius, Lithuania, 2008; pp. 266-275.

20. Girdzijauskas, S.; Cepinskis, J.; Jurkonyte, E. Transformations in insurance market: Modern accounting method of insurance tariffs. Transform. Bus. Econ. 2008, 7, 143-153.

21. Burns, A.; Mitchell, W. Measuring Business Cycles; National Bureau of Economic Research: New York, NY, USA, 1946; p. 560.

22. Mensch, G. Stalemate in Technology-Innovations Overcome the Depression; Ballinger: New York, NY, USA, 1979.

23. Sterman, J.D. Business Dynamics: Systems Thinking and Modeling for a Complex World; McGraw-Hill Higher Education: Columbus, OH, USA, 2000; p. 950. 
24. Sornette, D. Why Stock Markets Crash: Critical Events in Complex Financial Systems; Princeton University Press: Princeton, NJ, USA, 2003.

25. Schumpeter, J.A. Business Cycles. A Theoretical, Historical and Statistical Analysis of the Capitalist Process; McGraw-Hill Book Company: New York, NY, USA, 2008.

26. French, D.E. Early Speculative Bubbles and Increases in the Supply of Money; Ludwig von Mises Institute: Auburn, Alabama, USA, 2009; p. 133. Available online: http://mises.org/Books/ bubbles.pdf (accessed on 23 October 2012).

27. Kindleberger, C.P. Manias, Panics, and Crashes: A History of Financial Crises; Basic Books: New York, NY, USA, 1996.

28. Dubnikovas, M.; Moskaliova, V.; Girdzijauskas, S. Analysis of the share price bubbles in the Baltic countries. LNBIP 2009, 37, 119-129.

29. Girdzijauskas, S.A.; Streimikiee, D.; Dubnikovas, M. Analyzing banking capital with LOGLET lab software package. Transform. Bus. Econ. 2009, 8, 45-56.

30. Girdzijauskas, S.; Dubnikovas, M. Logistic Analysis of Price Bubble and Current Situation in USA Real Estate. In Proceedings of Business Information Systems Workshops, Vilnius, Lithuania, September 2010; pp. 13-18.

(C) 2012 by the authors; licensee MDPI, Basel, Switzerland. This article is an open access article distributed under the terms and conditions of the Creative Commons Attribution license (http://creativecommons.org/licenses/by/3.0/). 